\title{
SMALL MAMMAL COMMUNITIES IN A RAPIDLY DEVELOPING SOUTHERN INDIAN CITY
}

\author{
Kausalya Shenoy ${ }^{1}$ and P.S. Madhusudan ${ }^{2}$ \\ ${ }^{1} 401$, Vijay Mansion Apts., $1^{\text {st }}$ Main, Vijayanagar 2nd stage, Bangalore, Karnataka 560040, India \\ 1,2 School of Biological Sciences, 101 Morgan Building, University of Kentucky, Lexington, KY 40506, USA (Corresponding address) \\ Emai: ${ }^{1}$ k19@uky.edu; ${ }^{2}$ madu@uky.edu
}

\begin{abstract}
Four sites around Bangalore city were chosen for survey of non-volant small mammals (rodents and insectivores). The sites were chosen in scrub patches and plantations that are typical of Bangalore landscape. Species composition, population and microhabitat preference were studied. The study assessed changes in species composition and community structure with the change in land use patterns and levels of anthropogenic disturbances. In areas of high anthropogenic disturbance, number of species, and abundance was recorded to be very low, as compared to areas of relatively low disturbance. Shivanahalli (least disturbed site, and most representative of wild habitats around Bangalore) recorded seven species, with Cremnomys blanfordi and Rattus rattus wroughtoni being dominant. Microhabitat preference was studied only in Shivanahalli, as the other sites did not have sufficient captures for analysis. Most of the captures were recorded in rocky areas, with dense shrub cover. The two dominant species appeared to avoid each other's territories.
\end{abstract}

\section{KEYWORDS}

Bangalore, Cremnomys blanfordi, rodents, Rattus rattus wroughtoni, small mammals, urban ecosystems.

Urban ecosystems harbour certain groups of wild taxa, of which small mammals form an important group. Small mammals can be defined as those mammals whose live weights do not exceed $5 \mathrm{~kg}$ when adult. These include members of orders Insectivora, Rodentia, Carnivora and Chiroptera (Stoddart, 1979). The study focussed on nocturnal insectivores and rodents.

Small mammals contribute to energy flow and nutrient cycling, and play important roles as seed predators, dispersal agents and pollination agents in tropical ecosystems, making them an important functional component of wild communities (Fleming, 1975; Chandrasekar-Rao \& Sunquist, 1996). They form important prey base for carnivores and raptors (Emmons, 1987; Hayward \& Phillipson, 1979). Some species like Bandicota bengalensis, Millardia meltada, Tatera indica and Mus booduga are abundantly found in agro-ecosystems (Tripathi et al., 2002), while some may be found in close association with humans: Rattus rattus and Mus musculus are commonly found inside houses (Tripathi et al., 2002); rodents like Bandicota indica are found abundantly in urban areas in garbage dumps and sewers (Prater, 1971; Parshad, 1999). Several small mammals that have adapted to modified habitats, such as agricultural fields and urban developments, have established themselves as agricultural pests (eg. Bandicota bengalensis, Rattus rattus, Mus booduga, Millardia meltada, Tatera indica - Advani, 1987; Brooks et al., 1988; Parshad, 1999; Siddique \& Arshad, 2003; Lathiya et al., 2003) and disease carriers (eg. Rattus rattus, Bandicota indica - Gangadhar et al., 2000; also see Kao et al.,
1996; Chanteau et al., 1998; Tanskul et al., 1998; Ellis et al., 1999).

Small mammals comprise most of the known living mammals of the world (Fleming, 1979; Stoddart, 1979). They are an extremely successful group of animals due to their immense breeding potential and easy adaptability to a wide variety of habitats, thus enabling them to acquire cosmopolitan distribution (Southern, 1979). Though members of Rodentia and Insectivora constitute most of the threatened species of the world, they are relatively less studied as compared to other groups such as Carnivora, which add to only $6 \%$ of the global threatened species list, but are the highest studied mammalian group worldwide (Amori \& Gippoliti, 2000).

There appears to be little published scientific studies on small mammals (Rodentia and Insectivora) in Bangalore, except for a checklist compiled by Karthikeyan (1999). The present study inventoried the rodent and insectivore community of urban and rural Bangalore. Habitat associations were examined. Population estimates were attempted, but quantifiable data was obtained from only one site. Here populations and distributions were investigated in relation to microhabitats. The study also examined the change in land-use patterns and its influence on rodent community structure and diversity. This study was a preliminary attempt at understanding the small mammal community structure in semi-natural habitats around a rapidly growing urban ecosystem.

\section{Methodology \\ Study area}

The district of Bangalore in southern India lies between the latitudes $12^{0} 39^{\prime}-13^{0} 18^{\prime} \mathrm{N} \& 77^{0} 22^{\prime}-77^{0} 52^{\prime} \mathrm{E}$. It covers an area of $2191 \mathrm{~km}^{2}$, with Bangalore city occupying $151 \mathrm{~km}^{2}$, an area that is fast increasing. The temperatures in the district range from a summer average of $33^{\circ} \mathrm{C}$ and winter average of $14^{\circ} \mathrm{C}$. The average annual rainfall is $92 \mathrm{~cm}$ (Meteorological Centre, pers. com.).

The natural vegetation of Bangalore comprises of scrub forests. Typically the landscape of urban and rural Bangalore is a mosaic of scrub patches, plantations, orchards, agricultural fields and built-up areas. With the increase in urbanisation there has been a consequent significant decrease in natural and seminatural habitats (Behera et al., 1985), which are home to most urban wildlife. The sites chosen for the study represented the habitats surrounding Bangalore. Locating undisturbed patches was extremely difficult. Four sites were chosen, all within a distance of $30 \mathrm{~km}$ from the centre of the city.

(c) Zoo Outreach Organisation; www.zoosprint.org 
Site 1: The Bangalore University campus lies on the southwest outskirts of Bangalore city. The vegetation is a mix of scrub and Eucalyptus plantations. The area chosen for the study was a patch with such a mix. The campus is under moderate to high levels of anthropogenic pressure, with local people regularly collecting firewood and grass, and grazing their cattle. The grass is fired during the dry season to encourage new flush to provide fodder for the cattle.

Site 2: Gandhi Krishi Vidya Kendra (GKVK), or the Agricultural University Campus, lies on the northern outskirts of the city. The GKVK campus is mainly covered with Eucalyptus plantations, open fields, orchards and scrub vegetation. For the study, a Eucalyptus plantation and a small scrub patch were chosen. The ground cover in the Eucalyptus patch was extremely sparse. This region is also under moderate levels of anthropogenic pressure. Metalled and un-metalled roads crisscross the landscape, and people pass through and around it on a regular basis. We also observed that firewood is collected regularly.

Site 3: Shivanahalli, a village that is located on the borders of the Bannerghatta National Park, lies to the south of Bangalore city. The national park is comprised of scrub forest habitat sprawling across gently undulating rocky hills. The patch chosen for the study in Shivanahalli was a farm belonging to the Ramakrishna Mission Ashram. The farm, stretching down the slope of a rocky hill, is a mix of scrub and bamboo, as well as planted forest species, and teak and mango plantations. The land is fenced in, and is relatively undisturbed.

Site 4: Jindal, close to Hessarghatta, lies towards the western part of Bangalore. Hessarghatta, the biggest watershed area in Bangalore, is almost completely an agricultural region. The Jindal area is more of a mix of agricultural fields, plantations and industries. A farm was chosen for the study here, comprising of coconut and Persian lilac plantations. Farmhands working in the area, frequent removal and burning of weeds, and people moving from the main road to a lake situated behind the farm proved to be constant sources of disturbance.

\section{Methods}

Sampling was conducted in the months of January and February 2003 at sites 1, 2 and 3. Site 4 was sampled in May 2003.

Sampling was done representatively, keeping in mind the heterogeneity of the sampling site. The pattern of laying traps varied from site to site as described below, depending on habitat characteristics and feasibility. In all sites, Sherman traps were laid for a period of six consecutive nights - two nights of baiting and four nights of trapping. Baiting involved laying traps with bait through the night, and releasing trapped animals without recording measurements, the next morning. This was done in order to acclimatise the animals to the traps. Trapping, which was done after the animals were assumedly acclimatised, involved recording measurements of trapped animals after a night of baiting. Traps were laid between 1700 and 1830 hours, and checked between 0700 and 0900 hours daily. Trapped animals were released without marking on the first two nights of baiting. Animals trapped during the next 4 nights were marked, weighed, measured, sexed and released. Animals captured on the first night of trapping were marked by clipping fur on the left rump; those captured on the second night were clipped on the right rump, and on the third night were clipped on the back.

\section{Trap laying patterns at the different sites:}

Bangalore University Campus: The patch chosen for the study in this site was a narrow strip of land bound by roads on three sides, and traps were laid in three lines of 16 traps each in an area of $0.72 \mathrm{ha}$. A distance of $15 \mathrm{~m}$ separated the lines from each other, and traps in each line were separated from each other by a distance of $10 \mathrm{~m}$. Bait used was dry coconut and dry fish.

GKVK Campus: Traps were laid in the Eucalyptus plantation in a grid of $7 \times 7$, each trap being separated from the other by $10 \mathrm{~m}$. Bait used was dry coconut and dry fish. Trapping frequency was found to be extremely low, and after two trapping nights the methods and bait was changed to test if there was any change. The bait used was dry coconut and jaggery. The question of whether the animals were rather thinly distributed, was tested by removing 14 traps from two alternate lines in between. Thus some traps were separated from each other by $10 \mathrm{~m}$ and some by $20 \mathrm{~m}$. The 14 removed traps were laid in a small scrub patch in a random order, roughly at separations of $20 \mathrm{~m}$ from each other. A total area of 0.63 ha was sampled in GKVK.

Shivanahalli: Here the traps were laid in such a fashion as to represent all habitat types. Two lines of traps traps each were laid in the planted forest patch. The traps were placed $20 \mathrm{~m}$ from each other. The rest of the traps were placed in straight lines through all the habitat types. Inter trap distance in each line was $20 \mathrm{~m}$. The total area sampled was 2 ha. Bait used was jaggery and dry coconut. However, after two nights, the use of jaggery was discontinued as ants attracted by it bit animals that were trapped.

Jindal: Two patches - a coconut plantation and a Persian lilac patch - were chosen for the study. The Persian lilac patch was a rather square patch; traps were laid in a grid of $5 \times 5$, with $10 \mathrm{~m}$ spacing between traps. Another 25 traps were laid in the coconut plantation in three and a half lines of seven traps each, intertrap distance in each line being $10 \mathrm{~m}$, and the distance between the lines also measuring the same. The total area sampled measured was 0.5 ha. Dry coconut was used as bait.

Microhabitat parameters were recorded at each trap station in all four sites (Table 3).

Small mammals captured were identified on the field using Prater (1971) and Pradhan (2002). Unidentified animals were collected and preserved in 5\% formaldehyde solution for identification in the lab. Identification of samples was verified by Dr. Shakuntala Sridhara, University of Agricultural Sciences, Bangalore. 
Table 3. Parameters for assessing habitat were measured in a circle of radius $2 \mathrm{~m}$ around the trap station.

\begin{tabular}{|c|c|c|}
\hline S.No. & Parameters & Measurement \\
\hline 1 & Shrubs & Number of stems $<10 \mathrm{~cm}$ gbh \\
\hline 2 & Trees & Number of stems $>10 \mathrm{~cm}$ gbh \\
\hline 3 & Bamboo clumps & Number of clumps \\
\hline 4 & Ground cover & Percentage coverage (visual estimation) \\
\hline 4.1 & Grass- & Presence/absence \\
\hline 4.2 & Leaf litter & Presence/absence \\
\hline 5 & Canopy & $\begin{array}{l}\text { Scale of 0-3 (0- no canopy, } 1 \text { - branches } \\
\text { not meeting, } 2 \text { - branches just meeting, } \\
\text { 3- branches overlapping). Percentage } \\
\text { coverage (visual estimate) }\end{array}$ \\
\hline 6 & Soil substrate & Percentage coverage (visual estimate) \\
\hline 7 & Rock substrate & Distance in meters from trap station \\
\hline 8 & Distance to nearest tree & $\begin{array}{l}\text { Presence/absence of strata I, II, III } \\
\text { (strata I: } 0-1 \mathrm{~m} \text {, }\end{array}$ \\
\hline 9 & Stratification & strata II: $1-2 m$, strata III: $2-5 m)$ \\
\hline
\end{tabular}

\section{Data Analysis}

The following variables were analysed.

1. Species composition represents the proportion of each species captured among all the captured animals.

Total number of individuals of $i^{\text {th }}$ species $x 100$

Species composition $=\frac{\text { Total no. of captures of small mammals }}{\text { Tom }}$

This was calculated across all sites as well as separately for Shivanahalli.

2. Abundance

An index that reflects the abundance of rodents and insectivores at each site was calculated. This is given by

(Prakash \& Singh, 1999).

$$
\text { Trap Index (I) }=\frac{\text { Total number of captures } \times 100}{\text { No. of traps } \mathrm{x} \text { No. of trapping nights }}
$$

The same was calculated separately for the two dominant species in Shivanahalli, Cremnomys blanfordi and Rattus rattus wroughtoni.

3. The population was estimated using the Schnabel MarkRecapture method. In this method animals are captured and marked on several successive occasions. The method depends upon observing the increase in the proportion of marked animals captured in successive catches as the number of marked animals increase. When this proportion equals 1.0 , the total number of animals previously marked must be the number in the population (Sutherland, 1997).

The data was analysed using the regression method of Schumacher and Eschmeyer (Sutherland, 1997).

The total population size $(\mathrm{N})$ was estimated as

$\mathrm{N}=\mathrm{A} / \mathrm{B}$

where $\quad \mathrm{A}=\Sigma \mathrm{n}_{\mathrm{i}} \mathrm{M}_{\mathrm{i}}^{2}$

$\mathrm{B}=\Sigma \mathrm{m}_{\mathrm{i}} \mathrm{M}_{\mathrm{i}}$

where $n_{i}=$ number of animals in the $i^{\text {th }}$ sample $\mathrm{m}_{\mathrm{i}}=$ number of animals in $\mathrm{i}^{\text {th }}$ sample that are already carrying marks

$\mathrm{M}_{\mathrm{i}}=$ number of animals marked prior to the $\mathrm{i}^{\text {th }}$ sample, $\left\{\mathrm{M}_{\mathrm{i}}=\sum \mathrm{u}_{\mathrm{i}}, 1 \leq \mathrm{j} \leq \mathrm{i}-1\right\}$

$\mathrm{u}_{\mathrm{i}}=\mathrm{n}_{\mathrm{i}}-\mathrm{m}_{\mathrm{i}}=$ number of unmarked animals in $\mathrm{i}^{\text {th }}$ sample

$95 \%$ confidence limits for the population estimate was given by

$$
\mathrm{A} /\left\{\mathrm{B} \pm \mathrm{t} \sqrt{ }\left[\left(\mathrm{AC}-\mathrm{B}^{2}\right) /(\mathrm{S}-2)\right]\right\}
$$

where $\quad \mathrm{C}=\Sigma \mathrm{m}_{\mathrm{i}}^{2} / \mathrm{n}_{\mathrm{i}}$

$\mathrm{S}=$ number of samples

$\mathrm{t}=$ Student's $\mathrm{t}$ for S-2 degrees of freedom at the $5 \%$

significance level.

This was calculated only for the small mammal population of Shivanahalli, as other sites did not have sufficient number of captures or recaptures for estimating population.

4. Average weight of adults for each species was calculated across sites as well as for each site.

5. Sex ratio and ratio of adults to juveniles were calculated for dominant species in Shivanahalli only as the high number of captures made this possible.

6. Habitat

A Principal Component Analysis (PCA) was conducted to examine the habitat preferences of the small mammal community in Shivanahalli. Other sites did not have sufficient number of captures, and therefore they were not included in the analysis. Certain parameters were excluded, as they appeared redundant. The principal components were extracted by subjecting the data to a Varimax Normalised rotation. The test further assessed the habitat niche separation between the two dominant species in Shivanahalli.

MS Office Excel 2000 and STATISTICA 5.0 were used for the analyses.

\section{RESULTS}

A total of 43 individuals of eight species were captured from four sites. Bangalore University, GKVK and Jindal recorded only one species from each of the sites; we captured three individuals of Millardia meltada from each of Bangalore University and GKVK, and one individual of Suncus murinus from Jindal. Thrity-six individuals from seven species were recorded from Shivanahalli (Figure 2).

\section{Species composition}

The composition of small mammal taxa in Bangalore has been tabulated in Tables 1 and 2. Rattus rattus wroughtoni and Cremnomys blanfordi were the two dominant species captured during the study. The data has been represented graphically in Figures 1 and 2 .

Abundance

The abundance of small mammals was found to be highest at 


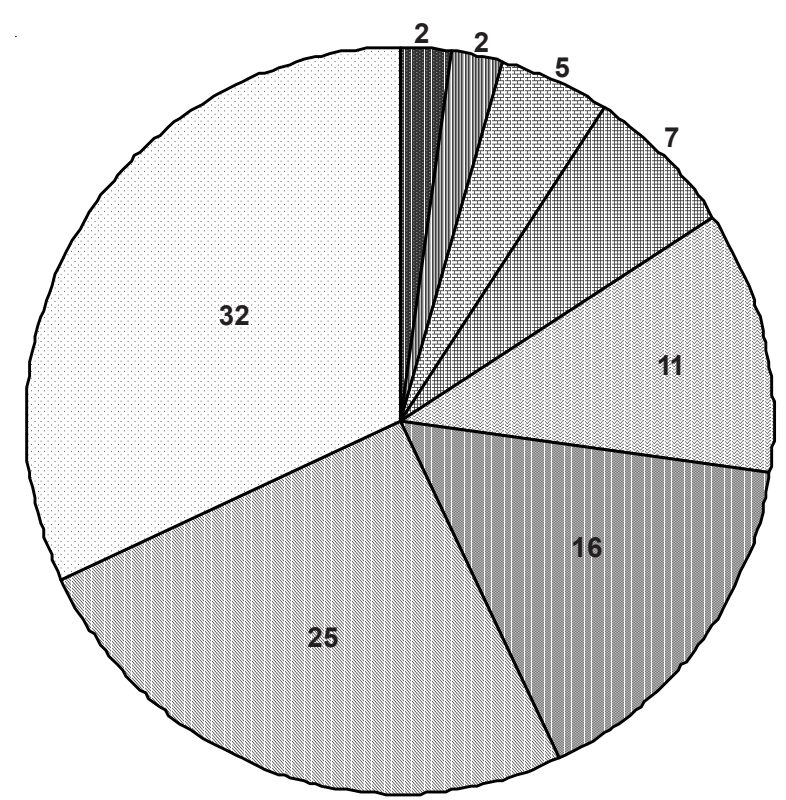

Numbers represent percentage composition of each species

Tatera indica Mus platythrix 关 Golunda ellioti $\square$ Millardia meltada

Rattus rattus wroughtoni $\square$ Cremnomys blanfordi

Figure 1. Species composition of small mammals captured in Bangalore.

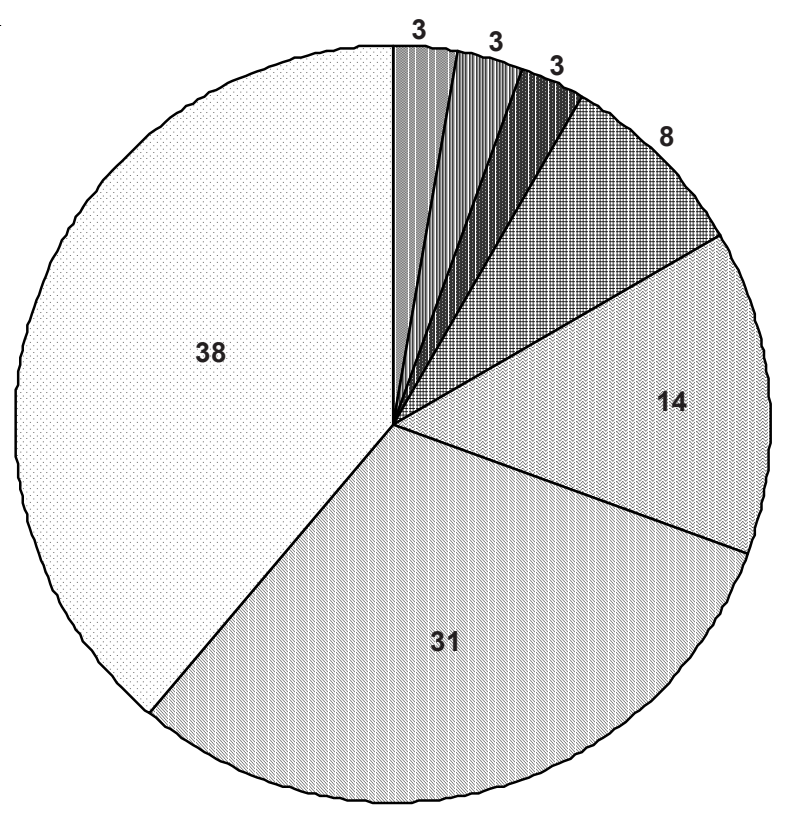

Numbers represent percentage composition of each species

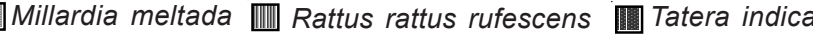
Mus platythrix 阅 Golunda ellioti $\square$ Rattus rattus wroughtoni Cremnomys blanfordi

Figure 2. Species composition of small mammals captured in Shivanahalli.
Table 1. Small mammal taxa captured during the study. These, along with species listed in Table 2, coincide with those recorded in Bangalore by Karthikeyan (1999).

\begin{tabular}{ll}
\hline Species & Common Name \\
\hline Tatera indica (Hardwicke, 1807) & Indian Gerbil \\
Rattus rattus rufescens (Gray) * & Common House Rat \\
Suncus murinus (Linnaeus, 1766) & Grey Musk Shrew \\
Mus platythrix (Bennett, 1832) & Spiny Field Mouse \\
Golunda ellioti (Gray, 1837) * & Indian Bush Rat \\
Millardia meltada (Gray, 1837) & Soft-furred Field Rat \\
Rattus rattus wroughtoni (Hinton) * & White-bellied Rat \\
Cremnomys blanfordi (Thomas, 1881) & White-tailed Wood Rat \\
\hline${ }^{*}$ represents species not recorded by Karthikeyan (1999).
\end{tabular}

Shivanahalli $(\mathrm{I}=18.37)$ and lowest at Jindal $(\mathrm{I}=0.50)$. Bangalore University $(\mathrm{I}=1.56)$ and GKVK $(\mathrm{I}=1.53)$ had comparatively low abundance. The two dominant species occurring at Shivanahalli were Rattus rattus wroughtoni $(\mathrm{I}=5.61)$ and Cremnomys blanfordi $(\mathrm{I}=6.63)$.

In GKVK, the increase in inter-trap distance did not affect capture rates. This is suggestive of the fact that the population itself is very low, and distribution is not patchy.

\section{Population}

Population of small mammals sampled within an area of 2 ha at Shivanahalli was estimated to be 80.17 individuals, within $95 \%$ confidence limits of 74.64 and 86.58. The populations of Rattus rattus wroughtoni and Cremnomys blanfordi in the same site were estimated at 12.45 and 18.76 , within $95 \%$ confidence limits of $11.71-13.30$ and $15.19-24.52$ respectively. The two species made up almost $70 \%$ of the animals captured, as can be seen from figure 2 .

\section{Average weight}

Average weight of adults of all species could not be calculated as adults of only Rattus rattus wroughtoni and Cremnomys blanfordi were captured from one site only (Shivanahalli). One adult Golunda ellioti was also captured here. Other species captured at this site were all juveniles, and similarly all animals captured at other sites were also juveniles.

At Shivanahalli, the average weight of Rattus rattus wroughtoni was $59.2 \mathrm{~g}$ and Cremnomys blanfordi was $97.83 \mathrm{~g}$. The single Golunda ellioti captured weighed $32 \mathrm{~g}$.

\section{$\underline{\text { Sex ratio }}$}

Males of both the dominant species at Shivanahalli seemed to be captured more frequently than females. The ratio of male to female animals captured at Shivanahalli for Rattus rattus wroughtoni and Cremnomys blanfordi were 8:3 and 9:2 respectively.

The ratio of adults to juveniles for Rattus rattus wroughtoni and Cremnomys blanfordi individuals captured at Shivanahalli were $10: 1$ and $3: 8$ respectively.

Combining data from all sites, $51 \%$ of all captured animals were 
Table 2. Other rodent taxa not encountered in the traps, but have been observed by the investigators within Bangalore urban city as well as in the study sites.

\begin{tabular}{lll}
\hline Species & Common name & Habitat where observed \\
\hline $\begin{array}{ll}\text { Funambulus palmarum (Linnaeus, 1766) } \\
\text { Bandicota indica (Bechstein, 1800) }\end{array}$ & Indian Palm Squirrel & urban, semi-urban, plantation and natural scrub habitats \\
$\begin{array}{l}\text { Bandicota bengalensis (Gray and Hardwicke, 1833) } \\
\text { Mus musculus (Linnaeus, 1758) }\end{array}$ & Larger Bandicoot Rat & within urban limits \\
Rattus rattus rattus (Linnaeus, 1758) & Common House Mouse & within urban limits \\
Vandeleuria oleracea (Bennett, 1832) & European Black Rat & inside house within urban limits \\
& Long-tailed Tree Mouse & inside house within urban limits \\
scrub habitat in Shivanahalli
\end{tabular}

juveniles or sub-adults, and 35\% were adults (14\% unknown).

\section{$\underline{\text { Habitat }}$}

The PCA extracted three components that accounted for $65.67 \%$ of the total variance. Six of the nine habitat parameters included for the test were found to be significant (Table 4). Principal Component 1 (PC 1) combined the mutually correlated parameters leaf litter, canopy and rock; PC 2 represented trees and bamboo, and PC 3 corresponded to shrub cover.

Scatter plots (Figure 3) illustrated the importance of each of these with respect to occurrence of small mammals.

It was seen that large numbers of small mammals were captured around rocky areas, having low level of canopy and leaf litter. The animals were found to have a slight preference for shrub cover, though this was not significant.

Graphs showing habitat preference were plotted for the two dominant species (Figure 4). There was no clear separation of habitat preference of the two species as seen from the graphs. However Rattus rattus wroughtoni seemed to be a more generalist species, while Cremnomys blanfordi was more particular regarding microhabitats used.

Rattus rattus wroughtoni is likely to be found in rocky regions with less canopy and leaf litter. It seemed to have a preference for open areas, but some individuals were captured from regions having some shrub cover. Further, the graphs (Fig. 4) indicated non-specificity with respect to trees and bamboos.

Clustering of data points on the graph was seen for Cremnomys blanfordi. This species had a preference for areas that were less open with some amount of shrub cover. This was also observed on the field. Trap stations where Cremnomys blanfordi were captured had less rock and higher levels of canopy and leaf litter as compared to stations where Rattus rattus wroughtoni were captured.

It was observed that in sections where Rattus rattus wroughtoni were captured in large numbers, Cremnomys blanfordi were either not captured or captured in low numbers, and vice versa (Fig. 5). There was overlap in some sections, but in general it appeared that the two did not venture into each other's territory. Trap stations 1 to 10 seem to be the domain of Cremnomys blanfordi, stations 11 to 20 that of Rattus rattus wroughtoni, and so on. There was some overlap in stations 44 to 49 . However, it can be seen that each species was never captured in the station where the other had been captured. The Spearman's rank correlation between numbers of Rattus rattus wroughtoni and numbers of Cremnomys blanfordi captured at each trap station was $-0.87(\mathrm{p}=0.000001)$.

\section{Discussion}

Over the past few decades, Bangalore has expanded tremendously in area, from roughly $67 \mathrm{~km}^{2}$ in 1961 to six times that in 1991 (Krishna et al., 1995), and is still growing rapidly. The city has seen a diminishing trend in natural and semi-natural habitats with the increase in industrialisation and urbanisation (Behera et al., 1985).

Among the four sites, Jindal had the highest levels of disturbance and Shivanahalli had the lowest. The study site in Jindal was a monoculture farm surrounded by industrial setups, and was an isolated patch of semi-natural habitat. Shivanahalli was a mosaic of agricultural land, plantations and the natural scrub habitat of Bannerghatta National Park. Bangalore University and GKVK campuses had monoculture patches of Eucalyptus sp., though Bangalore University was different in having layers of shrub and grass cover. While the habitat in Shivanahalli was heterogeneous, that of Jindal was almost homogeneous in its structure. GKVK and Bangalore University were also homogeneous, though less so compared to Jindal. Studies have attributed healthy communities of small mammals (with respect to population, density and species composition) to heterogeneity in habitat (Chandrasekar-Rao \& Sunquist, 1996), contiguity and habitat quality (Meena, 1997). There were marked differences in the population characteristics of small mammals in Shivanahalli when compared to the other three sites. Seven species captured in Shivanahalli was rather

Table 4. Habitat descriptors summarized by Principal Component Analysis. Factor loadings $>0.7$ were considered important components of their respective Principle Components (PC).

\begin{tabular}{|c|c|c|c|}
\hline & PC 1 & PC 2 & PC 3 \\
\hline Eigen values & 3.42 & 1.33 & 1.16 \\
\hline Cumulative variance (\%) & 38.00 & 52.78 & 65.67 \\
\hline \multicolumn{4}{|l|}{ Habitat parameters: } \\
\hline Shrubs & 0.10667 & 0.06320 & 0.89092 \\
\hline Trees & 0.43238 & -0.73169 & -0.02140 \\
\hline Bamboos & 0.42583 & 0.80043 & 0.07629 \\
\hline Ground Cover & 0.69674 & -0.03613 & 0.04937 \\
\hline Grass & -0.64852 & -0.05629 & -0.00565 \\
\hline Leaf Litter & 0.70708 & -0.10645 & 0.35723 \\
\hline Canopy & 0.78037 & 0.09941 & 0.09145 \\
\hline Rock & -0.74385 & 0.06892 & 0.45537 \\
\hline Distance to nearest tree & -0.63133 & 0.33501 & -0.30811 \\
\hline
\end{tabular}



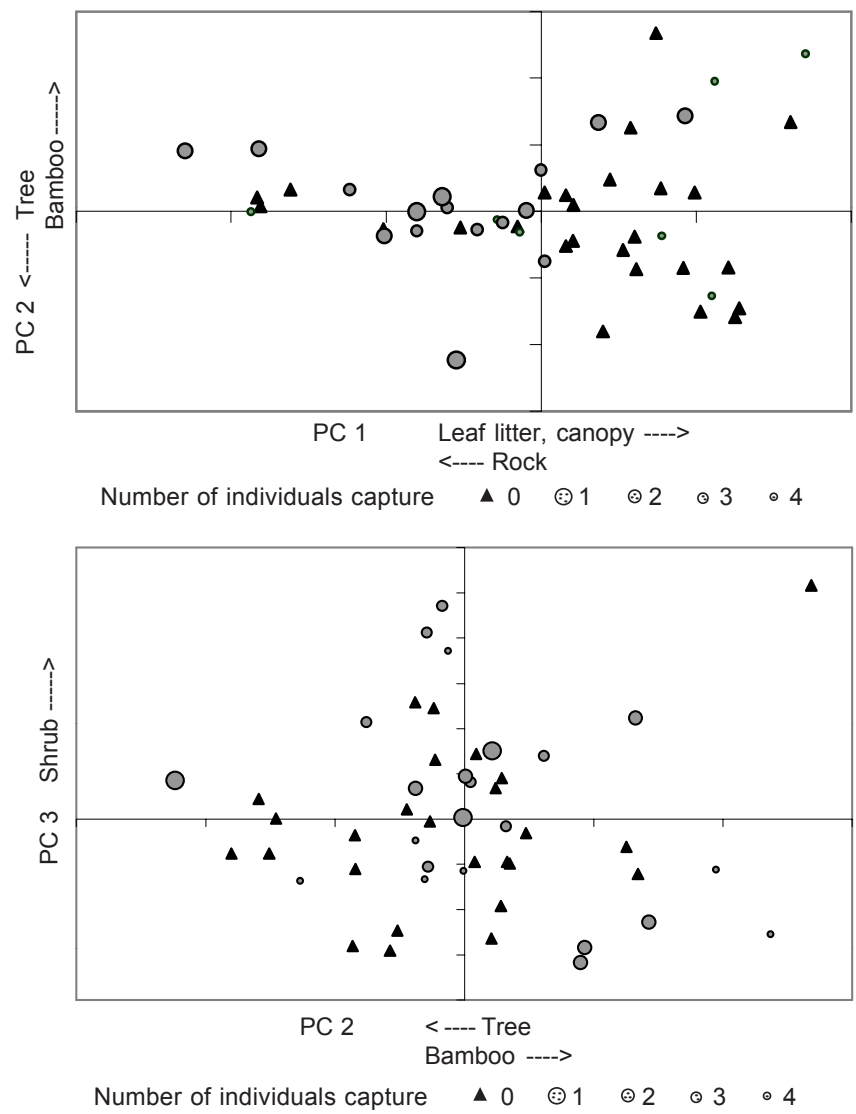

Figure 3. Number of small mammals captured in Shivanahalli and its relation to microhabitat parameters.

contrasting to one species captured elsewhere. Similar patterns were also seen in the case of abundance of small mammals in these areas (see results).

Suncus murinus, which was the only species captured in Jindal is commonly found in houses, and within cities and towns (Prater, 1971). Bangalore University and GKVK recorded Millardia meltada, which is indicative of the fact that the habitat tends towards openness and homogeneity; in India, this species has been recorded mostly in grasslands (Meena, 1997; Shanker, 2001), wattle plantations (Shanker, 2001) and agricultural fields (Prakash \& Singh, 1999; Shakuntala Sridhara, pers. com.).

\section{Microhabitat selection}

Microhabitat preference was examined only in Shivanahalli as other sites were deficient in the number of captures. Shivanahalli is the most natural of the habitats surveyed, and is representative of the wild habitats around Bangalore.

Preference for shrub cover, as seen in the results, could be related to predator avoidance (Chandrasekar-Rao \& Sunquist, 1996). Along similar lines, one would expect these animals to have a preference for high levels of canopy cover. But this was not seen in this study. A possible explanation could be that the dominant species were found in rocky areas that do not support dense growth of trees. Another could be that shrub cover
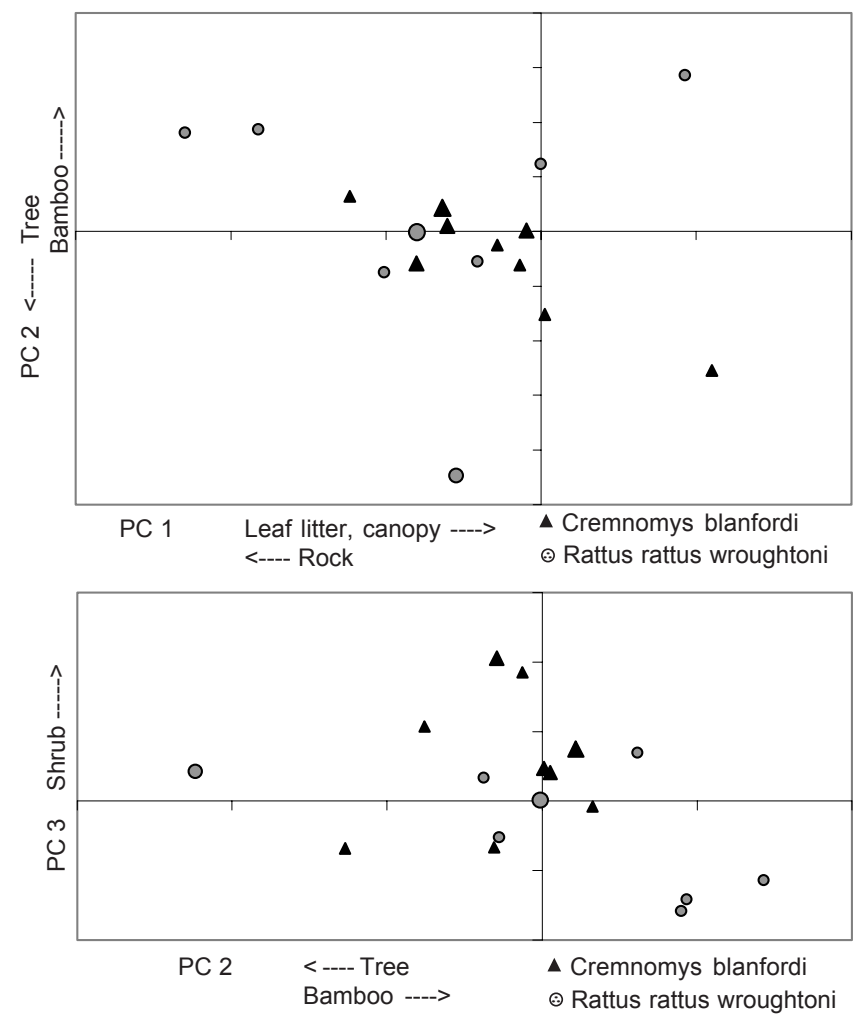

Figure 4. Habitat parameters and their importance to Rattus rattus wroughtoni and Cremnomys blanfordi in Shivanahalli. Increasing sizes of data points of either species implies increasing number of individuals captured.

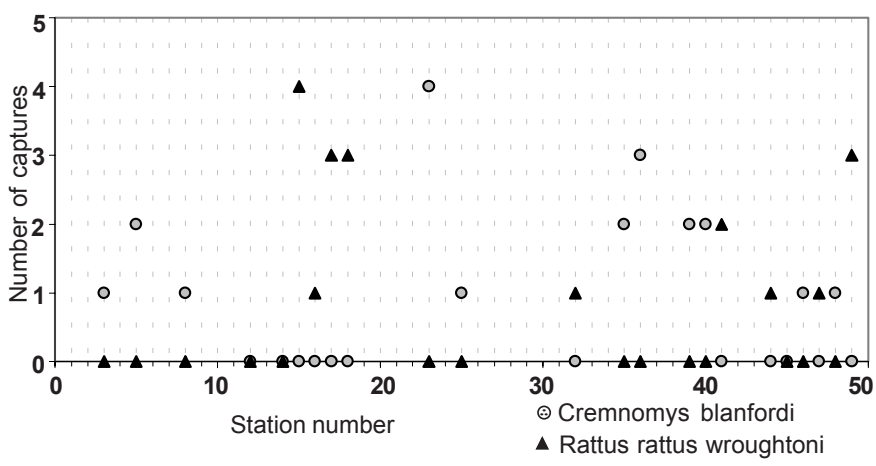

Figure 5. Distribution of Rattus rattus wroughtoni and Cremnomys blanfordi as reflected by capture data in Shivanahalli. Dotted vertical lines represent individual trap stations. The two species were never captured at the same trap stations.

offers more protection than canopy cover, which allows for some amount of openness up to some height above the ground level. Chandrasekar-Rao and Sunquist (1996) also found that high bamboo densities proved preferred habitats of small mammals in the Anaimalai hills of southern India. In Shivanahalli, a substantial number of rodents were captured in bamboo patches. However, this was not apparent from the analysis. The parameters were measured within a radius of $2 \mathrm{~m}$ around each trap station. Bamboo clumps did not grow densely; rather 
they were spread out somewhat thinly. Possibly, if parameters had been measured within a larger area around the stations, such discrepancies may have been avoided.

\section{Interspecific competition}

Small mammals are known to be highly competitive (Shanker, 2001). Competitition and habitat features may determine distribution and diversity of species in an area, but to what extent is not clear (Meena, 1997). With respect to micro-habitat selection, there was no significant segregation between the two dominant species Rattus rattus wroughtoni and Cremnomys blanfordi. While the former appeared to be somewhat generalist in its habitat usage, the latter was more specific, choosing to stay in areas having higher densities of shrubs. Rattus rattus wroughtoni favoured rocky regions more than Cremnomys blanfordi. The difference in site selection with respect to canopy cover was less significant between the two species. Meena (1997) found that the distributions of Rattus rattus and Cremnomys blanfordi were strongly negatively correlated. Shanker (2001) suggests that habitat selection by small mammals at the micro-habitat level is rather weak, but is definitely strong at the scale of the macro-habitat. This could not be tested in the present study, as sampling was not done across different macro-habitats.

Interestingly, though the segregation at the micro-habitat level was not discernable, territoriality between the two species was displayed, as was seen in their spatial distribution (see Results). The Spearman's correlation between numbers of each species captured at each trap station was strongly negative. Clearly the two species display strong territorial instincts and are mutually exclusive. Phillips (1981) remarks that Rattus rattus is a very adaptable and aggressive rodent and has been known to exclude other species from an area.

It is rather remarkable that most of the animals captured were sub-adults or juveniles, except in the case of Rattus rattus wroughtoni. Certain species were represented only by young ones, and no adults were captured. We speculate that juveniles disperse to establish territories, and more so the males, which would encounter opposition from other males. As this quest for a territory would continue for a somewhat extended period of time, the chances of a wandering juvenile male being captured is greater. It was found that the sex ratio of captured animals was biased in favour of males. This trend was seen in the case of adults of the two dominant species in Shivanahalli as well. Another possible explanation for this biased sex ratio could be the fact that males often tend to range over more extensive areas than females (Prakash, 1977) and are therefore more likely to be trapped. There is also the possibility that females are dispersing or are subjected to higher mortality rate than the males. Neither of these can be proved. Shanker and Sukumar (1998) suggest that in smaller patches, dispersal of females could lead to higher mortality or emigration, and therefore are less likely to be trapped.

Low populations in three of the four sites sampled have significant conservation implications. Populations at low densities are susceptible to local extinctions (ChandrasekarRao \& Sunquist, 1996). Rodent populations in disturbed habitats fluctuate much more than those in natural forest habitats (Isabirye-Basuta \& Kasenene, 1987). Disturbance levels appear to have an effect on characteristics of small mammal community structure. Firewood collection, cattle grazing, burning of pastures observed on Bangalore University campus are obvious threats to an already dwindling population. Shanker (1998) believes that the spread of plantations will alter the demography of small mammal communities in the wild, as well as that of carnivores dependent on them. The increase in urbanisation and fragmentation of natural and semi-natural habitats would demolish these communities entirely, allowing only for the hardy and adaptable species to thrive. The appreciable number of small mammals captured in Shivanahalli reinforces the fact that semi-natural habitats are pivotal in conserving these species. This is a key aspect for urban wildlife management - these species may not necessarily require heavily forested regions; rather habitat heterogeneity and semi-natural patches may be preserved in and around developed areas for the conservation of small mammal communities. It has been observed that in urban and suburban areas, small mammals are found in higher numbers in semi-natural heterogeneous patches than in manicured and groomed parks (Mahan \& O'Connell, 2005).

This study has only glimpsed into the world of small mammals inhabiting the semi-natural and agro-ecosystems around a rapidly expanding Indian city. Certain constraints such as time prevented us from further sampling that might have added interesting dimensions to this study, such as: were the higher abundance and diversity of small mammals in Shivanahalli an artefact of the habitat type or a consequence of contiguous natural and semi-natural habitats? This could be easily tested by sampling in various habitat types (Eucalyptus plantations, for example) around Shivanahalli and Bannerghatta, and comparing with similar habitat types in other areas that are not contiguous with natural habitats. More detailed studies building on similar questions would provide deeper insights into the effects of urbanization and development on small mammal communities, the understanding of which is crucial to conservation of these animals, as well as other aspects of urban ecosystems.

\section{REFERENCES}

Advani, R. (1987). Rodent Damage to Various Annual and Perennial Crops of India and Its Management. Paper presented at the 8th Wildlife Damage Control Workshop (Rapid City, SD, April 28-30, 1987).

Amori, G. and S. Gippoliti (2000). What do mammalogists want to save? Ten years of mammalian conservation biology. Biodiversity and Conservation 9: 785-793.

Behera, G., P.P. Nageshwara Rao, C.B.S. Dutt, B. Manikiam, P. Balakrishnan, J. Krishnamurthy, K.M. Jagadeesh, K. Ganesha Raj, P.G. Diwakar, A.S. Padmavath and R. Parvathy (1985). Growth of Bangalore city since 1900 based on maps and satellite imagery. ISRO Technical Report Number isro-eos-tr-55-85.

Brooks, J.E., E. Ahmad and I. Hussain (1988). Characteristics of damage by vertebrate pests to groundnuts in Pakistan. Vertebrate Pest Conference Proceedings collection, Proceedings of the Thirteenth Vertebrate Pest Conference, University of Nebraska, Lincoln, USA. 
Chandrasekar-Rao, A. and M.E. Sunquist (1996). Ecology of small mammals in tropical forest habitats of southern India. Journal of Tropical Ecology 12: 561-571.

Chanteau, S., L. Ratsifasoamanana, B. Rasoamanana, L. Rahalison, J. Randriambelosoa, J. Roux and D. Rabeson (1998). Plague, a reemerging disease in Madagascar. Emerging Infectious Diseases 4(1): 101-104.

Ellis, B.A., R.L. Regnery, L. Beati, F. Bacellar, M. Rood, G.G. Glass, E. Marston, T.G. Ksiazek, D. Jones, J.E. Childs (1999). Rats of the genus Rattus are reservoir hosts for pathogenic Bartonella species: an Old World origin for a New World disease? Journal of Infectious Diseases 180(1): 220-224.

Emmons, L.H. (1987). Comparative feeding ecology of fields in a Neotropical rainforest. Behavioral Ecology and Sociobiology 20: 271283.

Fleming, T.H. (1975). The role of small mammals in tropical ecosystems, pp.269-298. In: Golley, F.B., K. Petrusewicz and L. Rysxkowski (eds.). Small Mammals: Their Productivity and Population Dynamics. Cambridge University Press, New York, 451pp.

Fleming, T.H. (1979). Life history strategies, pp.1-61. In: Stoddart, D.M. (ed). Ecology of Small Mammals. Chapman and Hall, London. $386 \mathrm{pp}$.

Gangadhar, N.L., M. Rajasekhar, L.D. Smythe, M.A. Norris, M.L. Symonds and M.F. Dohnt (2000). Reservoir hosts of Leptospira inadai in India. Rev. sci. tech. Off. int. Epiz. 19(03): 793-799.

Hayward, G.F. and J. Phillipson (1979). Community structure and functional role of small mammals in ecosystems, pp.135-212. In: Stoddart, D.M. (ed). Ecology of Small Mammals. Chapman and Hall, London, 386pp.

Isabirye-Basuta, G. and J.M. Kasenene (1987). Small rodent populations in selectively felled and mature tracts of Kibale Forest, Uganda. Biotropica 19: 260-266.

Kao, C.L., C.J. Chen, T.S. Yen, J.C. Lien and C.S. Yang (1996). Seroepidemiology of Hantaan virus infection in Taiwan. Journal of Medical Virology 50(4): 309-313.

Karthikeyan, S. (1999). The vertebrates and butterflies of Bangalore: A checklist. WWF-India Karnataka Office, Bangalore.

Krishna, M.B., B.K. Chakrapani and C. Jayaram (1995). National lakes conservation plan and proposal for Bangalore. Department of Environment and Forests, Government of Karnataka.

Lathiya, S.B., A.R. Khokhar and S.M. Ahmed (2003). Population dynamics of soft-furred field rat, Millardia meltada, in rice and wheat fields in central Punjab, Pakistan. Turkish Journal of Zoology 27: 155161.

Mahan, C.G. and T.J. O'Connell (2005). Small mammal use of suburban and urban parks in central Pennsylvania. Northeastern Naturalist 12(3): 307-314

Meena, V. (1997). Community ecology of small mammals in Mudumalai Wildlife Sanctuary, south India. Unpublished Masters thesis. Pondicherry University, Pondicherry, India.

Parshad, V.R. (1999). Rodent control in India. Integrated Pest Management Reviews 4: 97-126.

Phillips, W.W.A. (1981). Manual of the Mammals of Sri Lanka, Part II. Wildlife and Nature Protection Society of Sri Lanka, Colombo, 390pp. Pradhan, M.S. (2002). Collection preservation and identification techniques of rodent/ shrew specimens. Training workshop on Field techniques and taxonomy for conservation of rodents and insectivores, conducted by RISCINSA and Zoo Outreach Organization, Trichur, India. Prakash, I. (1977). Biology of the rodents of Rajasthan desert, pp.337352. In: Roonwal, M.L. (ed). The Natural Resources of Rajasthan. Vol. I. University of Jodhpur, Jodhpur.

Prakash, I. and P. Singh (1999). Species composition, relative abundance and altitudinal distribution of small mammals in the Aravalli montane range. International Journal of Ecology and Environmental Sciences 25: 37-49.

Prater, S.H. (1971). The book of Indian animals. Eleventh impression. Bombay Natural History Society. Oxford University Press, Calcutta, Chennai, Delhi, Mumbai.

Shanker, K. (1998). Community ecology of small mammals in montane ecosystems of the Nilgiris, southern India. PhD thesis, Indian Institute of Sciences, Bangalore, India.

Shanker, K. (2001). The role of competition and habitat in structuring small mammal communities in a tropical montane ecosystem in southern India. Journal of Zoology, London 253: 15-24.

Shanker, K. and R. Sukumar (1998). Community structure and demography of small-mammal populations in insular montane forests in southern India. Oecologia 116: 243-251.

Siddique, M. and M. Arshad (2003). Seasonal Changes in the Abundance of Bandicota bengalensis in Irrigated Croplands, Faisalabad, Pakistan. Asian Journal of Plant Sciences 2(1): 145-148.

Southern, H.N. (1979). Population processes in small mammals, pp. 63-101. In: Stoddart, D.M. (ed). Ecology of small mammals. Chapman and Hall, London, 386pp.

Stoddart, D.M. (1979). Ecology of small mammals. Chapman and Hall, London, 386pp.

Sutherland, W.J. (1997). Ecological census techniques. Low price edition. Cambridge University Press, Cambridge, 260-280pp.

Tanskul, P., K.J. Linthicum, P. Watcharapichat, D. Phulsuksombati, S. Mungviriya, S. Ratanatham, N. Suwanabun, J. Sattabongkot and G. Watt (1998). A new ecology for scrub typhus associated with a focus of antibiotic resistance in rice farmers in Thailand. Journal od Medical Entomology 35(4): 551-555.

Tripathi, R.S. (2002). Distribution of rodents in northern and western regions of India. Training workshop on Field techniques and taxonomy for conservation of rodents and insectivores, conducted by RISCINSA and Zoo Outreach Organization, Trichur, India.

Tripathi, R.S., V. Chaudhary and M. Idris (2002). Rodent pest management and conservation. Training workshop on Field techniques and taxonomy for conservation of rodents and insectivores, conducted by RISCINSA and Zoo Outreach Organization, Trichur, India.

\section{ACKNOWLEDGEMENTS}

We would like to thank the following people without whose help this project would not have been possible: Ms. Sally Walker and Mr. Sanjay Molur, Zoo Outreach Organisation, Coimbatore for giving us the opportunity to contribute to the knowledge of small mammals in India, and for providing funds for the same. Dr. Shakuntala Sridhara, Rodent Control Programme, University of Agricultural Sciences, Bangalore, for helping us identify rodent samples. Mr. P.R. Srinivasan and his family for allowing us the use of their farm in Shivanahalli. The Ramakrishna Mission Ashram for allowing us to lay traps within their premises at Shivanahalli. Ms. Lalitha Sripad for allowing us to lay traps on her farm 'Sputnik' at Jindal.

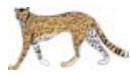

